\title{
The efficacy of surgery in advanced hepatocellular carcinoma: a cohort study
}

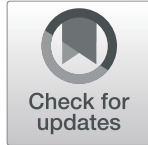

Lei Chen ${ }^{1,2,3 \dagger}$, Tao Sun ${ }^{1,2,3 \dagger}$, Shi Chen ${ }^{1,2}$, Yanqiao Ren ${ }^{1,2,3}$, Fan Yang ${ }^{1,2^{*}}$ and Chuansheng Zheng ${ }^{1,2,3^{*}}$ (D)

\begin{abstract}
Background: It is still controversial whether hepatocellular carcinoma (HCC) patients with lymph node invasion should receive surgery treatment. This study aimed to evaluate the efficacy of surgery (liver resection and local tumor destruction treatments) in HCC patients with regional lymph node metastasis.

Methods: The study utilized data from the Surveillance, Epidemiology, and End Results-18 (SEER-18) cancer registry. Patients for whom the treatment type was not clear or those with distant metastasis or without regional lymph nodule invasion were excluded. For survival analysis, patients with the survival months coded as 0 and 999 were excluded. All 1434 patients were included in the analysis. Among them, 168 patients were treated surgically and the other 1266 received non-surgery therapy. Propensity score matching (PSM) model was used to reduce selection bias.
\end{abstract}

Results: Before PSM, the median overall survival (mOS) and median cancer-specific survival (mCSS) of patients treated surgically were longer than that of receiving non-surgery treatment (mOS 20 months, 95\% Cl 15.3-24.7 vs. 7 months, $95 \% \mathrm{Cl} 6.4-7.6, P<0.001$; mCSS 21 months, 95\% Cl 115.5-26.5 vs. 6 months, $95 \% \mathrm{Cl}$ 5.3-6.7, $P<$ 0.001). Subgroup analysis found no significant differences in mOS and MCSS between liver resection and nonliver resection surgery cohorts $(P=0.886$ and $P=0.813$, respectively). Similar results were obtained in the PSM analysis. The mOS and mCSS in the surgery group were longer than those in the non-surgery group (mOS 20 months vs. 7 months, $P<0.001$; mCSS 20 months vs. 6 months, $P<0.001$ ). The multivariate analysis documented that surgery was an independent predictor for OS and CSS before and after PSM.

Conclusions: HCC patients with invasion of regional lymph nodules may get more survival benefit from surgery than other types of treatment.

Keywords: Hepatocellular carcinoma, Surgery, Liver resection, Efficacy

\section{Introduction}

Hepatocellular carcinoma (HCC) is one of the most common and lethal cancers $[1,2]$. The incidence of HCC in the USA might be double by 2030 [3]. Patients with early HCC can have a high 5-year survival rate after transplantation, or liver resection, or ablation treatment [4-6]. However, typically, about $70-80 \%$ of the patients

\footnotetext{
*Correspondence: fyang@vip.163.com; hqzcsxh@sina.com

${ }^{\dagger}$ Lei Chen and Tao Sun contributed equally to this work.

'Department of Radiology, Union Hospital, Tongji Medical College, Huazhong University of Science and Technology, Wuhan 430022, China Full list of author information is available at the end of the article
}

are diagnosed with $\mathrm{HCC}$ in the intermediate or advanced stage for there are no obvious clinical symptoms in early-stage HCC, and the radical treatments are not suitable for these people. HCC patients with intrahepatic vascular infiltration, regional lymph nodule invasion, or metastases to distant organs, and patients with cancerrelated symptoms (symptomatic tumors, Eastern Cooperative Oncology Group, ECOG 1-2) are diagnosed as advanced HCC according to the guideline, and treatment with molecular target drugs is recommended [2]. The SHARP trial demonstrated that, in comparison with placebo, sorafenib prolongs the survival of patients with

(c) The Author(s). 2020 Open Access This article is licensed under a Creative Commons Attribution 4.0 International License which permits use, sharing, adaptation, distribution and reproduction in any medium or format, as long as you give appropriate credit to the original author(s) and the source, provide a link to the Creative Commons licence, and indicate if changes were made. The images or other third party material in this article are included in the article's Creative Commons licence, unless indicated otherwise in a credit line to the material. If material is not included in the article's Creative Commons licence and your intended use is not permitted by statutory regulation or exceeds the permitted use, you will need to obtain permission directly from the copyright holder. To view a copy of this licence, visit http://creativecommons.org/licenses/by/4.0/ The Creative Commons Public Domain Dedication waiver (http://creativecommons.org/publicdomain/zero/1.0/) applies to the data made available in this article, unless otherwise stated in a credit line to the data. 
advanced HCC by approximately 4 months [7]. However, many patients discontinue the therapy because they cannot bear the complications of the drugs, which limited the effectiveness; as a result, only a small fraction of patients respond to pharmacologic treatment. Therefore, it is worth considering other treatments that may prolong the survival of patients with advanced HCC.

The current guideline does not recommend surgery for the treatment of advanced HCC patients [2]. However, it has been proposed that patients with regional vascular, lymph node, or organ invasion, or limited distant metastases should not be defined as advanced cancer. Conversely, they should be considered as the stage between intermediate and late stages since they could get a better survival benefit through surgery [8]. Recent data indicate that HCC patients with regional lymph node invasion or several metastasizes might receive the survival benefit from liver resection, ablation, radiotherapy, or transarterial chemoembolization (TACE) [9-13]. Although these studies presented encouraging results regarding the efficacy of surgery in patients with advanced HCC, the insufficient number of cases included in the analysis limits the strength of the conclusions reached.

The benefit of surgery in HCC patients with regional lymph nodule invasion remains unclear. Moreover, no randomized controlled trial (RCT) was conducted to address this issue. Therefore, the goal of the present study was to analyze the efficacy of surgery on HCC patients with regional lymph nodule invasion based on records available in the Surveillance, Epidemiology, and End Results-18 (SEER-18) database.

\section{Methods}

This study utilized the information from a publicly available cancer registry, SEER-18. The database includes approximately $28 \%$ of the US population (Connecticut, San Francisco, Iowa, Detroit, New Mexico, Alaska Native Registry, Seattle, Hawaii, Utah, Atlanta, San JoseMonterey, rural Georgia, Los Angeles, Kentucky, New Jersey, California [excluding San Francisco, San JoseMonterey, and Los Angeles], Louisiana, and Georgia [excluding Atlanta and rural Georgia]). SEER-18 includes information on the site and extent of disease, treatment modality, patient survival, and demographic data.

The analysis included patients aged 30-84 years, diagnosed with HCC (International Classification of Diseases for Oncology, Third Edition (ICD-O-3), histology code 8170-8175, site code C22.0 (liver)) from 2004 to 2015. Patients for whom the treatment type was not clear or those with distant metastasis (including organs and lymph nodules) or without regional lymph nodule invasion were excluded. For survival analysis, patients with the survival months coded as 0 and 999 were excluded. A total of 1434 patients (all of them were AJCC 6th IIIC,
TXN1M0-T4N1M0) were included in the study, 168 of them were treated surgically (including liver resection and local tumor destruction, cryoablation, percutaneous ethanol injection, radiofrequency ablation, and other), and 1266 received non-surgical treatment (Supplementary Figure 1). In the surgery group, 4 patients received radiotherapy before the surgery and 7 patients received radiotherapy after the surgery. The characteristics of patients before propensity score matching (PSM) are listed in Table 1.

\section{Study outcomes}

The endpoint of this study was patient death. The overall survival (OS) of patients was defined from the time of HCC diagnosis to death. Cancer-specific survival was defined as the time from HCC diagnosis to death caused by cancer.

\section{Statistical analysis}

The data were extracted using the SEER*Stat software (version 8.3.6). Categorical variables were analyzed by the chi-square test and Fisher's exact test. OS and CSS were plotted by the Kaplan-Meier method and compared by the log-rank test. Predictors for OS and CSS were analyzed by the Cox proportional risk model. In the research, the survival time was taken as dependent variables based on the model to analyze the influence of a lot of factors on survival. To reduce collinearity caused by some factors, we did not conduct univariate analysis, but conduct multivariate analysis directly. Multivariate analysis included the characteristics of gender, age, ethnicity, marital status, American Joint Committee on Cancer (AJCC) 6th T stage, year of diagnosis, tumor size, number of tumors, and the type of treatment (Table 2).

Propensity score matching (PSM) was used to reduce potential confounding effects and selection bias. The characteristics of gender, age, ethnicity, marital status, AJCC 6th T stage, year of diagnosis, tumor size, number of tumors, and the type of treatment were included in PSM assessment. A total of 608 patients were generated by a 1:4 ratio matching with an optimal caliper of 0.2 . The characteristics of patients after PSM are listed in Table 3.

All statistical analyses were performed using GraphPad Prism 8.0 (GraphPad Software, San Diego, CA) and SPSS v24.0 (IBM, Chicago, IL, USA) software.

\section{Results}

\section{Survival analysis}

Before PSM, the mOS in the surgery group (20 months, 95\% CI 15.3-24.7) was longer than that in the nonsurgery group (7 months, 95\% CI 6.4-7.6), and patients with surgery had higher survival rate than patients with non-surgery (HR 0.476, 95\% CI 0.397, 0.571) (Fig. 1a). In 
Table 1 The baseline characteristics of patients before PSM

\begin{tabular}{|c|c|c|c|}
\hline \multirow[t]{2}{*}{ Characteristics } & \multicolumn{2}{|c|}{ All patients, no. (\%), 1434 (100) } & \multirow[t]{2}{*}{$P$ value } \\
\hline & Surgery, 168 (11.7) & Non-surgery, 1266 (88.3) & \\
\hline Gender & & & 0.363 \\
\hline Male & $135(80.4)$ & $1053(83.2)$ & \\
\hline Female & $33(19.6)$ & $213(16.8)$ & \\
\hline Age at diagnosis & & & 0.225 \\
\hline $30-44$ & $7(4.2)$ & $27(2.1)$ & \\
\hline $45-59$ & $72(42.8)$ & $499(39.4)$ & \\
\hline $60-74$ & $71(42.3)$ & $563(44.5)$ & \\
\hline $75-84$ & $18(10.7)$ & $177(14)$ & \\
\hline Ethnicity & & & 0.373 \\
\hline White & $119(70.8)$ & $871(68.8)$ & \\
\hline Black & $23(13.7)$ & $225(17.8)$ & \\
\hline Others & $26(15.5)$ & $170(13.4)$ & \\
\hline Marital status & & & 0.022 \\
\hline Married & $103(61.3)$ & $638(50.4)$ & \\
\hline Single & 57 (33.9) & $571(45.1)$ & \\
\hline Others & $8(4.8)$ & $57(4.5)$ & \\
\hline AJCC T stage & & & $<0.001$ \\
\hline $\mathrm{T} 1$ & $58(34.5)$ & $289(22.8)$ & \\
\hline $\mathrm{T} 2$ & $51(30.4)$ & $270(21.3)$ & \\
\hline T3 & $56(33.3)$ & $627(49.5)$ & \\
\hline T4 & $2(1.2)$ & $65(5.1)$ & \\
\hline TX & $1(0.6)$ & $15(1.2)$ & \\
\hline Year of diagnosis & & & $<0.001$ \\
\hline 2004-2006 & $49(29.2)$ & $178(14.1)$ & \\
\hline 2007-2009 & $49(29.2)$ & $249(19.7)$ & \\
\hline 2010-2012 & 28 (16.6) & $393(31)$ & \\
\hline 2013-2015 & $42(25)$ & $446(35.2)$ & \\
\hline Tumor size & & & 0.01 \\
\hline$\leq 3 \mathrm{~cm}$ & $38(22.6)$ & $181(14.3)$ & \\
\hline $3-5 \mathrm{~cm}$ & 39 (23.2) & 274 (21.6) & \\
\hline$>5 \mathrm{~cm}$ & $91(54.2)$ & $811(64.1)$ & \\
\hline Tumor number & & & 0.428 \\
\hline 1 & $142(84.5)$ & 1104 (87.2) & \\
\hline 2 & 19 (11.3) & $135(10.7)$ & \\
\hline 3 & $6(3.6)$ & $23(1.8)$ & \\
\hline$>3$ & $1(0.6)$ & $4(0.3)$ & \\
\hline Radiotherapy & & & 0.115 \\
\hline Yes & $11(6.5)$ & $132(10.4)$ & \\
\hline No & $157(93.5)$ & 1134 (89.6) & \\
\hline Chemotherapy & & & 0.046 \\
\hline Yes & 77 (45.8) & $684(54)$ & \\
\hline No & $91(54.2)$ & $582(46)$ & \\
\hline Liver resection & 69 & - & - \\
\hline
\end{tabular}


Table 1 The baseline characteristics of patients before PSM (Continued)

\begin{tabular}{lll}
\hline Characteristics & All patients, no. (\%), 1434 (100) & \\
\cline { 2 - 3 } & Surgery, 168 (11.7) & Non-surgery, $1266(88.3)$ \\
\hline Wedge or segmental resection & 27 & - \\
Lobectomy & 25 & - \\
Extended lobectomy & 14 & - \\
Hepatectomy & 3 & - \\
Non-liver resection & 99 & - \\
Local tumor destruction & 30 & - \\
Cryoablation & 2 & - \\
Percutaneous ethanol injection & 5 & - \\
Radiofrequency ablation & 55 & - \\
Others & 7 & - \\
\hline
\end{tabular}

the surgery group, the subgroup analysis showed that mOS in the liver resection group (16 months, 95\% CI 8.223.8) was similar to that in the non-liver resection group (22 months, 95\% CI 16.6-27.4) $(P=0.886)$ (Fig. 2a). In the liver resection subgroup, $\mathrm{mOS}$ of patients with liver resection combined with the removal of regional lymph nodes (14 months, 95\% CI 9.5-18.5) was similar with liver resection alone (24 months, 95\% CI 21.1-26.9) $(P=0.142)$ (Fig. $2 \mathrm{c})$. The mOS of patients with liver resection was longer than the mOS of patients with non-surgery $(P<0.001)$ (Supplementary Figure 2A). However, the mOS of patients with liver resection combined with the removal of regional lymph nodes was similar with the mOS of patients with non-liver resection $(P=0.354)$ (Supplementary Figure 2C).

Similar results were obtained in the analysis of CSS. The mCSS of patients treated surgically (21 months, 95\% CI 15.5-26.5) was longer than in patients subjected to non-surgical treatment (6 months, 95\% CI 5.3-6.7), and patients with surgery had lower cancer-specific death rate than patients with non-surgery (HR 0.475, 95\% CI $0.389,0.580$ ) (Fig. 1b). In the subgroup analysis of the surgery group, the mCSS in patients with liver resection (18 months, 95\% CI 10-26) was slightly shorter than that in patients treated without liver resection surgery (21 months, 95\% CI 15.4-26.6) $(P=0.813)$ (Fig. 2b). The $\mathrm{mCSS}$ in patients with liver resection alone (25 months, 95\% CI 20-30) was longer than with liver resection combined with lymph node removal (14 months, 95\% CI 9.5-18.5) $(P=0.058)$ (Fig. 2d). The mCSS of patients with liver resection was longer than the mCSS of patients with non-surgery $(P<0.001)$ (Supplementary Figure $2 \mathrm{~B}$ ). However, the mCSS of patients with liver resection combined with the removal of regional lymph nodes was similar with the mCSS of patients with nonliver resection $(P=0.226)$ (Supplementary Figure 2D).

After PSM, the mOS and mCSS in the surgery group (mOS 20 months, 95\% CI 15.1-24.9; mCSS 20 months,
95\% CI 14.6-25.4) were longer than those in the nonsurgery group (mOS 7 months, 95\% CI 5.9-8.1; mCSS 6 months, 95\% CI 4.8-7.2) $(P<0.001$ for both $\mathrm{mOS}$ and mCSS) (Fig. 3a, b).

\section{Predictors for OS and CSS}

Before PSM, the multivariate logistic regression analysis demonstrated that the treatments (non-surgery: HR 2.115; 95\% CI 1.789-2.501, $P<0.001$ ) were independent predictors for OS in advanced HCC patients. Older age, higher AJCC stage, larger tumor size, and without receiving radiotherapy, chemotherapy, and surgical treatment were associated with worse outcome in all patients (Table 2). For CSS, similar results were obtained in the multivariate logistic regression analysis for CSS. Older age, higher AJCC stage, larger tumor size, and without receiving radiotherapy, chemotherapy, and surgical treatment were all correlated with a shorter CSS of the patients (Table 2).

After PSM, the multivariate logistic regression analysis showed that older patients, patients with high AJCC T stage, larger tumor size, and without receiving radiotherapy, chemotherapy, and surgical treatment had worse OS and CSS (Table 4).

\section{Discussion}

The most widely adopted HCC staging system is based on the Barcelona Clinical Liver Cancer (BCLC) criteria [14]. BCLC staging is endorsed by the guidelines of the American Association for the Study of Liver Diseases (AASLD) and the European Association for the Study of the Liver (EASL) due to its ability to account for liver function, tumor burden, and prognosis prediction [2, 15]. The BCLC criteria recommend that early-intermediate HCC patients with good liver function (Child-Pugh A-B) and physical condition (ECOG 0) should be treated surgically (liver resection, liver transplantation or ablation for early HCC, and TACE) [14]. However, accumulating evidence 
Table 2 Multivariate analysis of predictors for mortality and cancer-specific death before PSM

\begin{tabular}{|c|c|c|c|c|}
\hline \multirow[t]{2}{*}{ Characteristics } & \multicolumn{4}{|l|}{ Multivariate analysis } \\
\hline & Overall survival, HR (95\% Cl) & $P$ value & Cancer-specific survival, HR (95\% Cl) & $P$ value \\
\hline \multicolumn{5}{|l|}{ Gender } \\
\hline Male & Reference & & Reference & \\
\hline Female & $1.104(0.950,1.282)$ & 0.196 & $0.982(0.826,1.167)$ & 0.833 \\
\hline \multicolumn{5}{|c|}{ Age at diagnosis } \\
\hline $30-44$ & Reference & & Reference & \\
\hline $45-59$ & $1.493(1.025,2.173)$ & 0.037 & $1.725(1.132,2.627)$ & 0.011 \\
\hline $60-74$ & $1.487(1.023,2.162)$ & 0.038 & $1.768(1.160,2.692)$ & 0.008 \\
\hline $75-84$ & $1.586(1.068,2.357)$ & 0.022 & $1.842(1.176,2.884)$ & 0.008 \\
\hline \multicolumn{5}{|l|}{ Ethnicity } \\
\hline White & Reference & & Reference & \\
\hline Black & $0.955(0.823,1.109)$ & 0.548 & $0.914(0.772,1.084)$ & 0.302 \\
\hline Others & $0.914(0.773,1.082)$ & 0.914 & $0.946(0.788,1.136)$ & 0.551 \\
\hline \multicolumn{5}{|l|}{ Marital status } \\
\hline Married & Reference & & Reference & \\
\hline Single & $1.010(0.898,1.135)$ & 0.869 & $1.040(0.913,1.186)$ & 0.554 \\
\hline Others & $0.988(0.749,1.303)$ & 0.931 & $1.066(0.793,1.433)$ & 0.674 \\
\hline \multicolumn{5}{|l|}{ AJCC T stage } \\
\hline $\mathrm{T} 1$ & Reference & & Reference & \\
\hline $\mathrm{T} 2$ & $1.165(0.980,1.385)$ & 0.084 & $1.230(1.09,1.500)$ & 0.040 \\
\hline T3 & $1.418(1.217,1.652)$ & $<0.001$ & $1.412(1.189,1.677)$ & $<0.001$ \\
\hline $\mathrm{T} 4$ & $1.703(1.294,2.240)$ & $<0.001$ & $1.881(1.398,2.529)$ & $<0.001$ \\
\hline TX & $1.443(0.868,2.400)$ & 0.157 & $1.343(0.729,2.474)$ & 0.344 \\
\hline \multicolumn{5}{|c|}{ Year of diagnosis } \\
\hline 2004-2006 & Reference & & Reference & \\
\hline 2007-2009 & $0.948(0.791,1.137)$ & 0.564 & $0.973(0.794,1.191)$ & 0.789 \\
\hline 2010-2012 & $1.197(1.009,1.421)$ & 0.039 & $1.175(0.970,1.424)$ & 0.100 \\
\hline 2013-2015 & $1.109(0.930,1.322)$ & 0.251 & $1.070(0.878,1.303)$ & 0.503 \\
\hline \multicolumn{5}{|l|}{ Tumor size } \\
\hline$\leq 3 \mathrm{~cm}$ & Reference & & Reference & \\
\hline $3-5 \mathrm{~cm}$ & $1.305(1.080,1.577)$ & 0.006 & $1.432(1.151,1.781)$ & 0.001 \\
\hline$>5 \mathrm{~cm}$ & $1.685(1.392,2.039)$ & $<0.001$ & $1.857(1.487,2.318)$ & $<0.001$ \\
\hline \multicolumn{5}{|l|}{ Tumor number } \\
\hline 1 & Reference & & Reference & \\
\hline 2 & $0.872(0.727,1.046)$ & 0.141 & $0.740(0.461,1.186)$ & 0.210 \\
\hline 3 & $0.577(0.368,0.904)$ & 0.016 & $N$ & 0.879 \\
\hline$>3$ & $1.528(0.631,3.702)$ & 0.348 & $N$ & $N$ \\
\hline \multicolumn{5}{|l|}{ Radiotherapy } \\
\hline Yes & Reference & & Reference & \\
\hline No & $1.550(1.281,1.876)$ & $<0.001$ & $1.524(1.230,1.888)$ & $<0.001$ \\
\hline \multicolumn{5}{|l|}{ Chemotherapy } \\
\hline Yes & Reference & & Reference & \\
\hline No & $1.664(1.485,1.865)$ & $<0.001$ & $1.772(1.559,2.015)$ & $<0.001$ \\
\hline \multicolumn{5}{|l|}{ Surgery } \\
\hline Yes & Reference & & Reference & \\
\hline No & $2.118(1.756,2.555)$ & $<0.001$ & $2.115(1.789,2.501)$ & $<0.001$ \\
\hline
\end{tabular}


Table 3 The baseline characteristics of patients after PSM

\begin{tabular}{|c|c|c|c|}
\hline \multirow[t]{2}{*}{ Characteristics } & \multicolumn{3}{|c|}{ All patients, no. (\%), 608 (100) } \\
\hline & Surgery, 165 (27.1) & Non-surgery, 443 (72.9) & $P$ value \\
\hline Gender & & & 0.977 \\
\hline Male & $135(81.8)$ & $362(81.7)$ & \\
\hline Female & $30(18.2)$ & $81(18.3)$ & \\
\hline Age at diagnosis & & & 0.765 \\
\hline $30-44$ & $7(4.2)$ & $12(2.7)$ & \\
\hline $45-59$ & $69(41.8)$ & $179(40.4)$ & \\
\hline $60-74$ & $71(43.1)$ & $201(45.4)$ & \\
\hline $75-84$ & $18(10.9)$ & $51(11.5)$ & \\
\hline Ethnicity & & & 0.511 \\
\hline White & $116(70.3)$ & $324(73.1)$ & \\
\hline Black & $23(13.9)$ & $65(14.7)$ & \\
\hline Others & $26(15.8)$ & $54(12.2)$ & \\
\hline Marital status & & & 0.284 \\
\hline Married & $100(60.6)$ & $257(58)$ & \\
\hline Single & $57(34.5)$ & $174(39.3)$ & \\
\hline Others & $8(4.9)$ & $12(2.7)$ & \\
\hline AJCC T stage & & & 0.635 \\
\hline $\mathrm{T} 1$ & $55(33.4)$ & $145(32.7)$ & \\
\hline $\mathrm{T} 2$ & $51(30.9)$ & $121(27.3)$ & \\
\hline T3 & $56(33.9)$ & $159(35.9)$ & \\
\hline T4 & $2(1.2)$ & $14(3.2)$ & \\
\hline TX & $1(0.6)$ & $4(0.9)$ & \\
\hline Year of diagnosis & & & 0.228 \\
\hline 2004-2006 & $46(27.9)$ & $107(24.2)$ & \\
\hline 2007-2009 & 49 (29.7) & $116(26.2)$ & \\
\hline 2010-2012 & $28(17)$ & $109(24.6)$ & \\
\hline 2013-2015 & $42(25.4)$ & $111(25)$ & \\
\hline Tumor size & & & 0.532 \\
\hline$\leq 3 \mathrm{~cm}$ & 37 (22.4) & $84(19)$ & \\
\hline $3-5 \mathrm{~cm}$ & $38(23)$ & $117(26.4)$ & \\
\hline$>5 \mathrm{~cm}$ & 90 (54.6) & $242(54.6)$ & \\
\hline Tumor number & & & 0.208 \\
\hline 1 & $141(85.5)$ & $402(90.7)$ & \\
\hline 2 & $18(10.9)$ & $34(7.7)$ & \\
\hline 3 & $5(3)$ & $5(1.1)$ & \\
\hline$>3$ & $1(0.6)$ & $2(0.5)$ & \\
\hline Radiotherapy & & & 0.796 \\
\hline Yes & $11(6.7)$ & $27(6.1)$ & \\
\hline No & $154(93.3)$ & 416 (93.9) & \\
\hline Chemotherapy & & & 0.950 \\
\hline Yes & 77 (46.7) & $208(47)$ & \\
\hline No & $88(53.3)$ & $235(53)$ & \\
\hline Liver resection & 68 & & - \\
\hline
\end{tabular}


Table 3 The baseline characteristics of patients after PSM (Continued)

\begin{tabular}{|c|c|c|c|}
\hline \multirow[t]{2}{*}{ Characteristics } & \multicolumn{3}{|c|}{ All patients, no. (\%), 608 (100) } \\
\hline & Surgery, 165 (27.1) & Non-surgery, 443 (72.9) & $P$ value \\
\hline Wedge or segmental resection & 27 & - & \\
\hline Lobectomy & 24 & - & \\
\hline Extended lobectomy & 14 & - & \\
\hline Hepatectomy & 3 & - & \\
\hline Non-liver resection & 97 & & - \\
\hline Local tumor destruction & 30 & - & \\
\hline Cryoablation & 2 & - & \\
\hline Percutaneous ethanol injection & 5 & - & \\
\hline Radiofrequency ablation & 53 & - & \\
\hline Others & 7 & - & \\
\hline
\end{tabular}

supports the conclusion that patients with intermediate HCC can obtain a better survival benefit from liver resection than from TACE [16-18], and patients with advanced $\mathrm{HCC}$ can get good efficacy from surgery alone or in combination with other treatments [19].

Patients with advanced HCC often have poor survival outcomes due to cancer-related impairment of liver function or physical condition. Previous studies documented that advanced HCC patients with lymph node invasion or metastases had median survival times of 6-8 months $[20,21]$. However, the same group of patients treated with molecular targeted drugs, surgery alone, or a combination of both therapies could expect longer survival times of 7.0-20.4 months [7, 22-25]. In these analyses, the combination of surgery with molecular targeted drugs or with another surgery often resulted in longer mOS. Duffy and coworkers have found that patients with advanced HCC treated with the combination of tremelimumab and liver ablation had mOS of 12.3 months [26], which was longer than the mOS of patients treated with sorafenib alone [27]. A randomized phase II trial compared the efficacy of treatment by a combination of sorafenib and hepatic arterial infusion chemotherapy with that of using sorafenib alone, which has found that patients with combined therapies had longer mOS than that of single treatment [25]. The usage of surgical treatment for patients with advanced HCC is limited because it might lead to liver failure and early death. However, emergent new technologies, such as laparoscopic surgery, microwave ablation, and TACE with drugeluting beads, limit the damage of surgery to patients and liver function. Therefore, patients with Child-Pugh A or B might get survival benefit from surgery.

The current study demonstrated that mOS of patients with surgical treatment was 20 months before PSM, which was longer than in patients treated non-surgically included in previous studies presented (mOS 7.4-7.9 months) $[9,27,28]$. Kokudo and collaborators compared the efficacy of HCC patients with portal vein tumor thrombosis who received liver resection with who received other treatments, and found that patients with liver resection had longer mOS than those not subjected to liver resection [29]. Similar results were obtained in the present study; patients with liver resection had
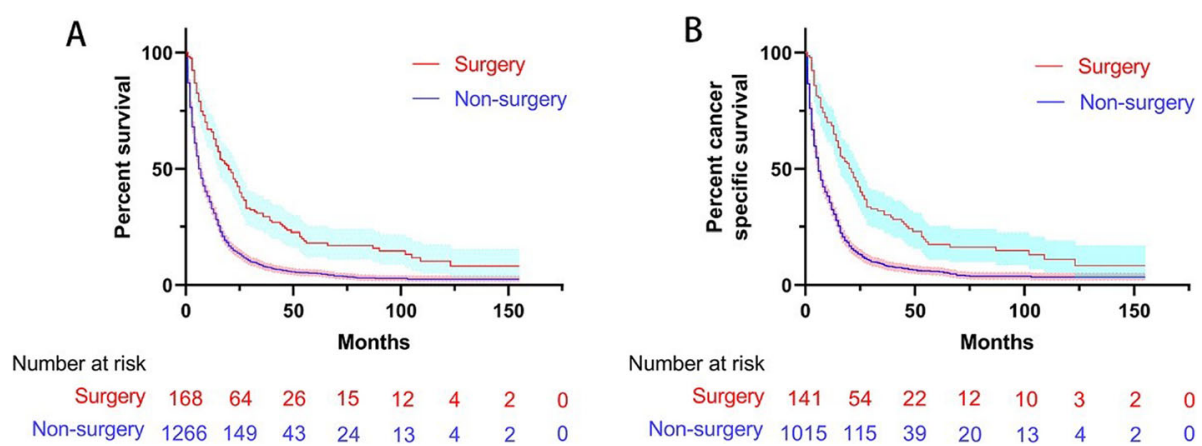

Fig. 1 Kaplan-Meier curve of overall survival (a) and cancer-specific survival (b) of patients with surgery and non-surgery treatment before PSM; the shaded area indicates the $95 \%$ confidence interval 

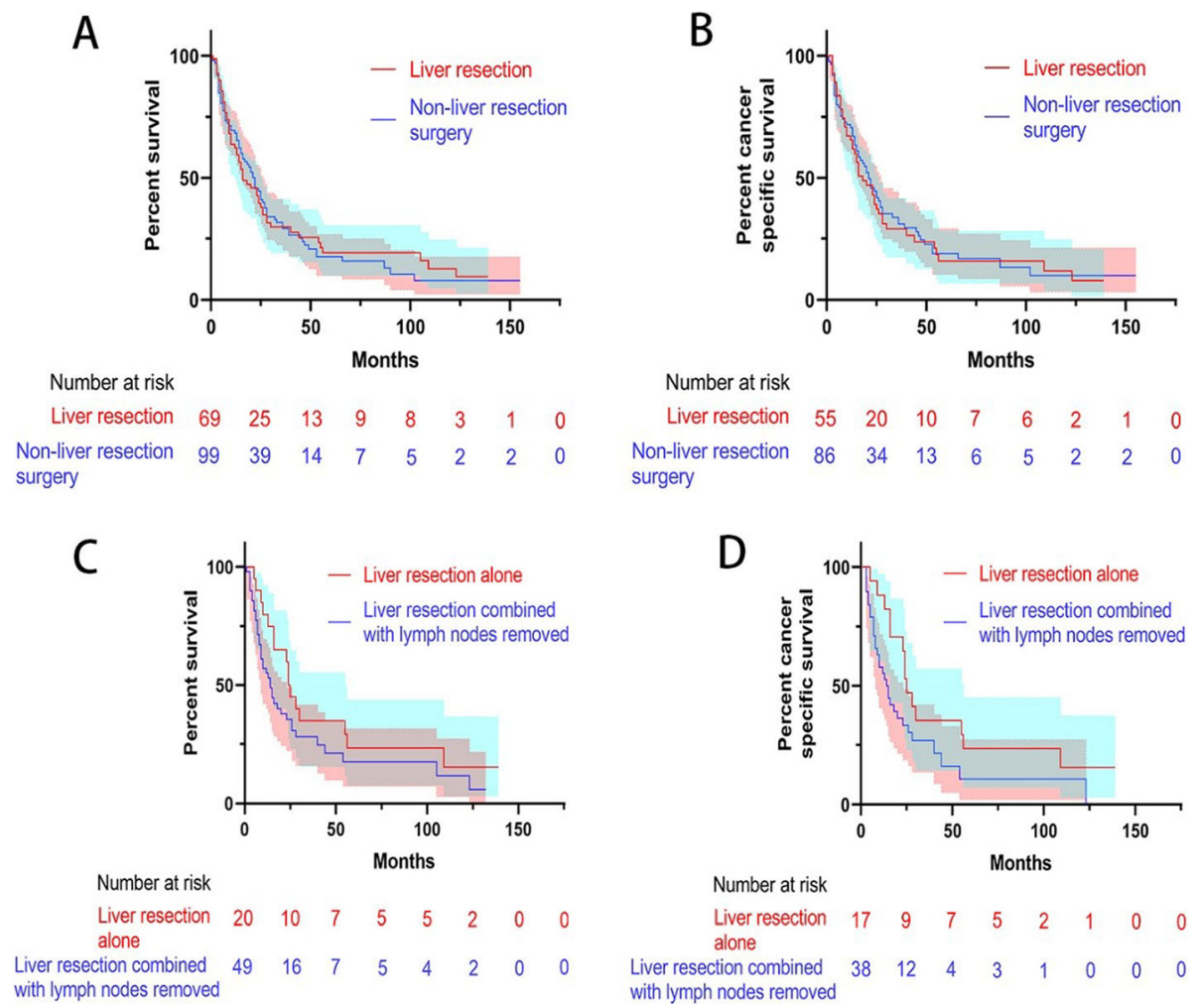

Fig. 2 Kaplan-Meier curve of overall survival and cancer-specific survival of patients. a The overall survival of patients with liver resection and nonliver resection treatment. $\mathbf{b}$ The cancer-specific survival of patients with liver resection and non-liver resection treatment. c The overall survival of patients with liver resection alone and liver resection combined with lymph node removal treatment. $\mathbf{d}$ The cancer-specific survival of patients with liver resection alone and liver resection combined with lymph node removal treatment; the shaded area indicates the $95 \%$ confidence interval

longer mOS than patients with non-surgical treatment. However, in a subgroup analysis, mOS in patients with liver resection was comparable to that in patients undergoing procedures (such as ablation), suggesting that liver resection might not be the preferred modality in patients with regional lymph node invasion. In the liver resection group, patients with liver resection and lymph nodes resection had no longer mOS than that of liver resection alone, and there was no difference in mCSS between the two groups. Our findings suggest that in patients treated with liver resection, it should be not recommended to remove regional lymph nodes. However, the findings are hypothesis-generating rather than conclusive, and further research in this area is required. After PSM and reduction of the selection biases and confounding effects, the mOS and mCSS in the surgery group were still
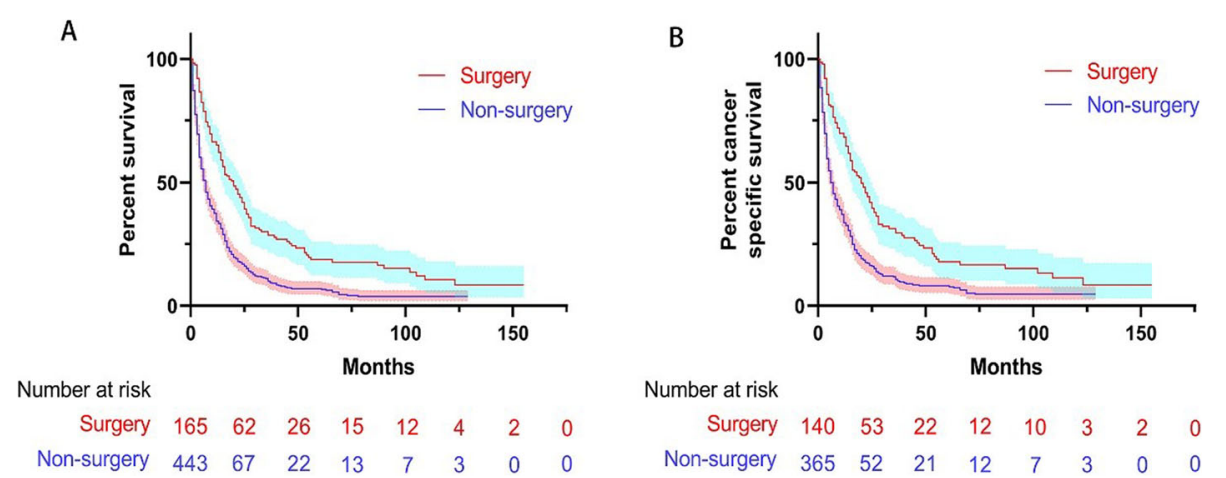

Fig. 3 Kaplan-Meier curve of overall survival (a) and cancer-specific survival (b) of patients with surgery and non-surgery treatment after PSM; the shaded area indicates the $95 \%$ confidence interval 
Table 4 Multivariate analysis of predictors for mortality and cancer-specific death after PSM

\begin{tabular}{|c|c|c|c|c|}
\hline \multirow[t]{2}{*}{ Characteristics } & \multicolumn{4}{|l|}{ Multivariate analysis } \\
\hline & Overall survival, HR (95\% Cl) & $P$ value & Cancer-specific survival, HR (95\% Cl) & $P$ value \\
\hline \multicolumn{5}{|l|}{ Gender } \\
\hline Male & Reference & & Reference & \\
\hline Female & $1.121(0.890,1.411)$ & 0.332 & $0.912(0.696,1.194)$ & 0.501 \\
\hline \multicolumn{5}{|c|}{ Age at diagnosis } \\
\hline $30-44$ & Reference & & Reference & \\
\hline $45-59$ & $2.384(1.369,4.153)$ & 0.002 & $2.874(1.539,5.365)$ & 0.001 \\
\hline $60-74$ & $2.397(1.382,4.158)$ & 0.002 & $3.055(1.645,5.674)$ & $<0.001$ \\
\hline $75-84$ & $2.631(1.456,4.757)$ & 0.001 & $3.059(1.562,5.993)$ & 0.001 \\
\hline \multicolumn{5}{|l|}{ Ethnicity } \\
\hline White & Reference & & Reference & \\
\hline Black & $0.913(0.706,1.181)$ & 0.490 & $0.844(0.634,1.121)$ & 0.844 \\
\hline Others & $0.8886(0.675,1.162)$ & 0.380 & $0.959(0.709,1.296)$ & 0.959 \\
\hline \multicolumn{5}{|l|}{ Marital status } \\
\hline Married & Reference & & Reference & \\
\hline Single & $0.968(0.800,1.172)$ & 0.741 & $1.026(0.832,1.264)$ & 0.812 \\
\hline Others & $1.323(0.792,2.209)$ & 0.285 & $1.429(0.837,2.442)$ & 0.191 \\
\hline \multicolumn{5}{|l|}{ AJCC T stage } \\
\hline $\mathrm{T} 1$ & Reference & & Reference & \\
\hline $\mathrm{T} 2$ & $1.324(1.044,1.679)$ & 0.021 & $1.381(1.054,1.811)$ & 0.019 \\
\hline T3 & $1.316(1.024,1.691)$ & 0.032 & $1.359(1.031,1.790)$ & 0.030 \\
\hline T4 & $1.766(1.028,3.034)$ & 0.039 & $1.682(0.941,3.008)$ & 0.079 \\
\hline TX & $1.462(0.588,3.633)$ & 0.413 & $1.322(0.478,3.661)$ & 0.591 \\
\hline \multicolumn{5}{|c|}{ Year of diagnosis } \\
\hline 2004-2006 & Reference & & Reference & \\
\hline 2007-2009 & $0.903(0.711,1.147)$ & 0.219 & $0.852(0.655,1.108)$ & 0.232 \\
\hline 2010-2012 & $1.027(0.798,1.322)$ & 0.834 & $0.932(0.701,1.239)$ & 0.627 \\
\hline 2013-2015 & $0.976(0.748,1.274)$ & 0.858 & $0.886(0.659,1.192)$ & 0.423 \\
\hline \multicolumn{5}{|l|}{ Tumor size } \\
\hline$\leq 3 \mathrm{~cm}$ & Reference & & Reference & \\
\hline $3-5 \mathrm{~cm}$ & $1.355(1.040,1.767)$ & 0.025 & $1.556(1.149,2.107)$ & 0.004 \\
\hline$>5 \mathrm{~cm}$ & $1.940(1.462,2.575)$ & $<0.001$ & $2.173(1.557,3.032)$ & $<0.001$ \\
\hline \multicolumn{5}{|l|}{ Tumor number } \\
\hline 1 & Reference & & Reference & \\
\hline 2 & $0.746(0.538,1.035)$ & 0.499 & $0.927(0.450,1.906)$ & 0.927 \\
\hline 3 & $0.307(0.125,0.754)$ & 0.010 & $N$ & 0.923 \\
\hline$>3$ & $1.546(0.483,4.954)$ & 0.463 & $N$ & $N$ \\
\hline \multicolumn{5}{|l|}{ Radiotherapy } \\
\hline Yes & Reference & & Reference & \\
\hline No & $1.765(1.194,2.607)$ & 0.004 & $1.931(1.262,2.953)$ & 0.002 \\
\hline \multicolumn{5}{|l|}{ Chemotherapy } \\
\hline Yes & Reference & & Reference & \\
\hline No & $1.660(1.383,1.991)$ & $<0.001$ & $1.852(1.510,2.271)$ & $<0.001$ \\
\hline
\end{tabular}

Surgery 
Table 4 Multivariate analysis of predictors for mortality and cancer-specific death after PSM (Continued)

\begin{tabular}{llll}
\hline Characteristics & Multivariate analysis & & \\
\cline { 2 - 4 } & Overall survival, HR $(95 \% \mathrm{Cl})$ & $P$ value & Cancer-specific survival, HR $(95 \% \mathrm{Cl})$ \\
\hline Yes & Reference & & Reference \\
No & $2.150(1.750,2.641)$ & $<0.001$ & $2.213(1.760,2.781)$ \\
\hline
\end{tabular}

longer than that of the non-surgery group $(P<0.001)$, supporting the conclusion that surgical treatment for HCC patients with regional lymph node invasion could obtain a better survival benefit than non-surgical approaches.

In multivariate logistic regression analysis, age at diagnosis, year of diagnosis, AJCC T stage, tumor size, radiotherapy treatment, chemoembolization treatment, and utilization of surgery were included in the analysis to reduce mutual influence among the variables. This approach documented that non-surgical treatment was an independent unfavorable factor for OS and CSS, whether or not PSM was performed. Patients not treated with surgery would have more than 2fold higher risk of overall death and cancer-specific death compared to patients undergoing surgery.

Liver function and physical condition of patients were not included in the current analysis as these characteristics were not recorded in the SEER database. The BCLC criteria define that patients with ECOG 1 should be classified as advanced HCC and should receive molecular targeted drugs or optimal supportive care. These patients were not included in this study, which might affect the accuracy of the results. However, patients with regional lymph node invasion were defined as having an advanced disease independently of liver function and physical condition. Thus, the study could still prove that surgery should be performed in advanced HCC patients who had good liver function and physical condition.

Although this analysis provided encouraging results, some limitations resulting from the historical design of the study should be acknowledged. First, the analysis utilized the SEER database which does not include the laboratory and imaging results; these variables might represent less precise predictors for OS and CSS. Second, selection biases may persist despite the use of the PSM model. However, PSM might be the best option to reduce selection biases since there are no RCTs or prospective studies focus on the issue presented in this analysis. Third, liver function, physical condition, whether patients received $\mathrm{R} 0$ resection, and that might influence the OS of patients were not incorporated in the current work, and the sample size was substantially smaller, which might lead to insufficient conclusion. Lastly, the number of invaded lymph nodules, lymphovascular invasion (LVI), and perineural invasion (PNI) which might influence the results of the study were not available and were not included in the study. Thus, we hope that future high-quality studies can confirm the findings of this study. All in all, compared with other types of treatments, patients with advanced HCC could get a better survival benefit through surgery. Lastly, despite the inclusion of many known confounders in the analysis and use of PSM, residual confounding cannot be excluded.

\section{Conclusions}

In conclusion, although the guidelines recommend molecular targeted drugs as the first-line treatment for advanced HCC patients, among them, patients with regional lymph node invasion might benefit more from surgery than other treatments; therefore, surgery might be a better therapy option for these patients.

\section{Supplementary information}

Supplementary information accompanies this paper at https://doi.org/10. 1186/s12957-020-01887-8.

Additional file 1: Figure S1. The flowchart of patients inclusion. Figure S2. Kaplan-Meier curve of overall survival and cancer-specific survival of patients; A: the overall survival of patients with liver resection and nonsurgery treatment; $B$ : the cancer-specific survival of patients with liver resection and non-surgery treatment; $\mathrm{C}$ : the overall survival of patients with non-liver resection and liver resection combined with lymph nodes removed treatment; D: the cancer-specific survival of patients with nonliver resection and liver resection combined with lymph nodes removed treatment; the shaded area indicates the 95\% Confidence Interval.

\section{Abbreviations}

HCC: Hepatocellular carcinoma; SEER: Surveillance, Epidemiology, and End Results; mOS: Median overall survival; mCSS: Median cancer-specific survival; PSM: Propensity score matching; ECOG: Eastern Cooperative Oncology Group; TACE: Transarterial chemoembolization; AJCC: American Joint Committee on Cancer

\section{Acknowledgements}

We acknowledged the SEER database for the provided data for the research.

\section{Authors' contributions}

Chuansheng Zheng and Fan Yang designed the research. Lei Chen and Tao Sun extracted the data from the SEER database. Lei Chen, Tao Sun, and Shi

Chen made statistical analysis. Lei Chen, Tao Sun, Shi Chen, and YanQiao Ren wrote the manuscript. Chuansheng Zheng and Fan Yang reviewed the manuscript. The authors read and approved the final manuscript.

\section{Funding}

This study was supported by the National Natural Science Foundation of China (81873919).

\section{Availability of data and materials}

The data could be found in the SEER database (https://seer.cancer.gov/ data/). 


\section{Ethics approval and consent to participate}

The research does not need to be reviewed by the ethics committee because the data were from the SEER database, and the written informed consent was exempted. However, the data used in the research was permitted by the SEER database management department.

\section{Consent for publication}

All authors approved for publication of the manuscript for the journal.

\section{Competing interests}

The authors declare that they have no competing interests.

\section{Author details}

'Department of Radiology, Union Hospital, Tongji Medical College, Huazhong University of Science and Technology, Wuhan 430022, China. ${ }^{2}$ Hubei Province Key Laboratory of Molecular Imaging, Wuhan 430022, China. ${ }^{3}$ Department of Interventional Radiology, Union Hospital, Tongji Medical College, Huazhong University of Science and Technology, Wuhan 430022, China.

Received: 8 February 2020 Accepted: 18 May 2020

Published online: 02 June 2020

\section{References}

1. Siegel RL, Miller KD, Jemal A. Cancer statistics, 2019. CA Cancer J Clin. 2019; 69:7-34.

2. EASL Clinical Practice Guidelines. Management of hepatocellular carcinoma. J Hepatol. 2018:69:182-236.

3. Kamarajah SK, Frankel TL, Sonnenday C, Cho CS, Nathan H. Critical evaluation of the American Joint Commission on Cancer (AJCC) 8th edition staging system for patients with hepatocellular carcinoma (HCC): a Surveillance, Epidemiology, End Results (SEER) analysis. J Surg Oncol. 2018; 117:644-50

4. Fonseca AL, Cha CH. Hepatocellular carcinoma: a comprehensive overview of surgical therapy. J Surg Oncol. 2014;110:712-9.

5. Luo W, Zhang Y, He G, Yu M, Zheng M, Liu L, Zhou X. Effects of radiofrequency ablation versus other ablating techniques on hepatocellular carcinomas: a systematic review and meta-analysis. World J Surg Oncol. 2017;15:126.

6. Duan C, Liu M, Zhang Z, Ma K, Bie P. Radiofrequency ablation versus hepatic resection for the treatment of early-stage hepatocellular carcinoma meeting Milan criteria: a systematic review and meta-analysis. World J Surg Oncol. 2013:11:190

7. Llovet JM, Ricci S, Mazzaferro V, Hilgard P, Gane E, Blanc JF, de Oliveira AC, Santoro A, Raoul JL, Forner A, et al. Sorafenib in advanced hepatocellular carcinoma. N Engl J Med. 2008;359:378-90.

8. Weichselbaum RR, Hellman S. Oligometastases revisited. Nat Rev Clin Oncol. 2011:8:378-82

9. Pan T, Xie QK, Lv N, Li XS, Mu LW, Wu PH, Zhao M. Percutaneous CT-guided radiofrequency ablation for lymph node oligometastases from hepatocellular carcinoma: a propensity score-matching analysis. Radiology. 2017:282:259-70.

10. Mu L, Sun L, Pan T, Lyu N, Li S, Li X, Wang J, Xie Q, Deng H, Zheng L, et al. Percutaneous CT-guided radiofrequency ablation for patients with extrahepatic oligometastases of hepatocellular carcinoma: long-term results. Int J Hyperth. 2018:34:59-67.

11. Wu H, Liu S, Zheng J, Ji G, Han J, Xie Y. Transcatheter arterial chemoembolization (TACE) for lymph node metastases in patients with hepatocellular carcinoma. J Surg Oncol. 2015;112:372-6.

12. Xiaohong S, Huikai L, Feng W, Ti Z, Yunlong C, Qiang L. Clinical significance of lymph node metastasis in patients undergoing partial hepatectomy for hepatocellular carcinoma. World J Surg. 2010;34:1028-33.

13. Kaizu T, Karasawa K, Tanaka Y, Matuda T, Kurosaki H, Tanaka S, Kumazaki T. Radiotherapy for osseous metastases from hepatocellular carcinoma: a retrospective study of 57 patients. Am J Gastroenterol. 1998:93:2167-71.

14. Forner A, Reig ME, de Lope CR, Bruix J. Current strategy for staging and treatment: the BCLC update and future prospects. Semin Liver Dis. 2010:30; $61-74$.

15. Bruix J, Sherman M. Management of hepatocellular carcinoma: an update Hepatology. 2011;53:1020-2.
16. Yin L, Li H, Li AJ, Lau WY, Pan ZY, Lai EC, Wu MC, Zhou WP. Partia hepatectomy vs. transcatheter arterial chemoembolization for resectable multiple hepatocellular carcinoma beyond Milan Criteria: a RCT. J Hepatol. 2014;61:82-8

17. Yang B, Zheng B, Yang M, Zeng Z, Yang F, Pu J, Li C, Liao Z. Liver resection versus transarterial chemoembolization for the initial treatment of Barcelona Clinic Liver Cancer stage B hepatocellular carcinoma. Hepatol Int. 2018;12: $417-28$.

18. Hyun MH, Lee YS, Kim JH, Lee CU, Jung YK, Seo YS, Yim HJ, Yeon JE, Byun KS. Hepatic resection compared to chemoembolization in intermediate- to advanced-stage hepatocellular carcinoma: a meta-analysis of high-quality studies. Hepatology. 2018;68:977-93.

19. Zhao Y, Wang WJ, Guan S, Li HL, Xu RC, Wu JB, Liu JS, Li HP, Bai W, Yin ZX, et al. Sorafenib combined with transarterial chemoembolization for the treatment of advanced hepatocellular carcinoma: a large-scale multicenter study of 222 patients. Ann Oncol. 2013;24:1786-92.

20. Cabibbo G, Enea M, Attanasio M, Bruix J, Craxi A, Camma C. A meta-analysis of survival rates of untreated patients in randomized clinical trials of hepatocellular carcinoma. Hepatology. 2010;51:1274-83.

21. Llovet JM, Bruix J. Systematic review of randomized trials for unresectable hepatocellular carcinoma: chemoembolization improves survival. Hepatology. 2003:37:429-42.

22. Suzuki E, Kaneko S, Okusaka T, Ikeda M, Yamaguchi K, Sugimoto R, Aramaki T, Asagi A, Yasui K, Sano K, et al. A multicenter phase II study of sorafenib in Japanese patients with advanced hepatocellular carcinoma and Child Pugh A and B class. Jpn J Clin Oncol. 2018:48:317-21.

23. Cosgrove DP, Reyes DK, Pawlik TM, Feng AL, Kamel IR, Geschwind JF. Openlabel single-arm phase II trial of sorafenib therapy with drug-eluting bead transarterial chemoembolization in patients with unresectable hepatocellular carcinoma: clinical results. Radiology. 2015;277:594-603.

24. Zhang Y, Fan W, Wang Y, Lu L, Fu S, Yang J, Huang Y, Yao W, Li J. Sorafenib with and without transarterial chemoembolization for advanced hepatocellular carcinoma with main portal vein tumor thrombosis: a retrospective analysis. Oncologist. 2015;20:1417-24.

25. Ikeda M, Shimizu S, Sato T, Morimoto M, Kojima Y, Inaba Y, Hagihara A, Kudo M, Nakamori S, Kaneko S, et al. Sorafenib plus hepatic arterial infusion chemotherapy with cisplatin versus sorafenib for advanced hepatocellular carcinoma: randomized phase II trial. Ann Oncol. 2016;27:2090-6.

26. Duffy AG, Ulahannan SV, Makorova-Rusher O, Rahma O, Wedemeyer H, Pratt D, Davis JL, Hughes MS, Heller T, ElGindi M, et al. Tremelimumab in combination with ablation in patients with advanced hepatocellular carcinoma. J Hepatol. 2017;66:545-51.

27. Palmer DH. Sorafenib in advanced hepatocellular carcinoma. N Engl J Med. 2008:359:2498 author reply 2498-2499.

28. Abou-Alfa GK, Qin S, Ryoo BY, Lu SN, Yen CJ, Feng YH, Lim HY, Izzo F, Colombo M, Sarker D, et al. Phase III randomized study of second line ADIPEG 20 plus best supportive care versus placebo plus best supportive care in patients with advanced hepatocellular carcinoma. Ann Oncol. 2018:29: $1402-8$

29. Kokudo T, Hasegawa K, Matsuyama Y, Takayama T, Izumi N, Kadoya M, Kudo M, Ku Y, Sakamoto M, Nakashima O, et al. Survival benefit of liver resection for hepatocellular carcinoma associated with portal vein invasion. J Hepatol. 2016;65:938-43.

\section{Publisher's Note}

Springer Nature remains neutral with regard to jurisdictional claims in published maps and institutional affiliations.

Ready to submit your research? Choose BMC and benefit from:

- fast, convenient online submission

- thorough peer review by experienced researchers in your field

- rapid publication on acceptance

- support for research data, including large and complex data types

- gold Open Access which fosters wider collaboration and increased citations

- maximum visibility for your research: over $100 \mathrm{M}$ website views per year

At BMC, research is always in progress.

Learn more biomedcentral.com/submissions 